\title{
SUBDURAL HAEMATOMA IN AN ADULT AFTER AIR ENCEPHALOGRAPHY
}

\author{
BY
}

\author{
R. G. ROBINSON
}

\author{
From the Department of Neurosurgery, Dunedin Hospital, and the University of Otago Medical School
}

Air encephalography in the absence of a spaceoccupying lesion of the brain is usually a harmless but unpleasant investigation that is necessary in the differential diagnosis of organic dementias and neurological syndromes of uncertain origin. It is known that subdural effusions may follow encephalography in children (Smith and Crothers, 1950). The development of a subdural haematoma in an adult after air studies has been rarely recorded. Such a complication has an important bearing on the management of the patient who occasionally deteriorates and may die after what has been considered to be a normal investigation.

\section{Case Report}

A man (NS 4512) aged 48 years, who was a barman, was admitted to the Neurosurgical Unit, Dunedin Hospital, on May 11, 1952. Eighteen months before he had fallen down some steps and had been unconscious for four hours. Two weeks later dull headaches at the back of the head began and persisted. There had been four attacks in this period when both his arms had been useless. He had had insomnia for six months; he had become depressed and lost weight.

On examination, he was very depressed and tearful and somewhat agitated. The optic disc margins were blurred. He had a very dubious weakness of the left arm. There were no other physical signs. Radiographs of the skull were normal and the calcified pineal shadow was centrally placed.

On February 14, a right carotid arteriogram was normal, and on February 18 a lumbar encephalogram was done using $40 \mathrm{ml}$. of air. This was considered to be normal. The cerebrospinal fluid had cells 0 , protein $40 \mathrm{mg}$. per $100 \mathrm{ml}$., and a zero colloidal gold curve. After the encephalogram the patient developed headaches of a bursting nature. He was very emotional. On February 26 the headaches were much worse and he had a sudden short period of blindness. The pupils were fixed and dilated for 10 minutes and then became normal. The next day he had poor upwards gaze, slight left facial weakness, weakness of the left arm, increased tendon jerks in the left arm and right leg and the right plantar response was extensor.

On March 4 he was very drowsy, the left pupil was fixed and dilated, there was a left ptosis, and the left plantar response was extensor. A left carotid arteriogram showed that the left cerebral vessels were displaced to the left by a right-sided mass.

On March 5, ventriculography (R.G.R.) was done by posterior burr holes under local anaesthesia. The ventricular pressure was sub-atmospheric. The radiographs showed a large right-sided mass. A right mid-parietal burr hole was made and a large subdural haematoma was evacuated. The brain expanded afterwards. The patient deteriorated and died that night.

At necropsy (Dr. R. Rodda) there was some residual blood in the right subdural space. The lining membrane was thin and thought to be consistent with a duration of two weeks. Bilateral uncinate grooving and tonsillar coning were present and there were numerous haemorrhages in the pons and midbrain. There was no microscopical cause in the brain for the original complaints.

This patient died because it was not realized soon enough that he might have a subdural haematoma as a result of the encephalogram. Earlier treatment would have saved him. It was thought that he had a midbrain tumour which had escaped radiological recognition. The encephalogram was done by the fractional method of Lindgren (1949). It has been assumed that his presenting symptoms were due to a post-concussional syndrome with depressive features in the lack of any structural alteration in the nervous system at necropsy other than those due to the subdural haematoma.

\section{Discussion}

There is general agreement that there are few complications from encephalography and that the fatality rate is about $\mathbf{0 . 2 \%}$ in a large series (Davidoff and Dyke, 1946; Whittier, 1951). Most of the deaths can be accounted for by deterioration in the presence of a previously unsuspected cerebral tumour. Many of the other deaths are when there is an organic dementia. Air embolism is an exceedingly rare complication (Whittier, 1951). It has only been possible to find one instance of subdural haematoma after encephalography in adults.

Bucy (1942) reported a case of a 66-year-old man with personality changes who had a lumbar en- 
cephalogram when $350 \mathrm{ml}$. cerebrospinal fluid was removed and replaced by air. The radiographs were normal but showed air in the subdural space. Afterwards he became stuporose and burr holes were made some three months later. Bilateral chronic subdural haematomas were found and removed. He recovered to his pre-encephalographic state.

Smith and Crothers (1950) considered that the subdural effusions in children after encephalography were due to collapse of the brain and tearing of the bridging veins of the subdural space. It is probable that the same explanation accounts for the adult cases. Air is common in the subdural space after this procedure (Lemere and Barnacle, 1936). McConnell (1953b) made burr holes on cases with air in the subdural space after encephalography and usually found collections of fluid like cerebrospinal fluid. It would appear that he used total cerebrospinal fluid replacement in his encephalography (McConnell, 1953a). Our case showed that a subdural haematoma may follow when only $40 \mathrm{ml}$. cerebrospinal fluid has been replaced by air and a gradual technique used.

The diagnosis of the patient who deteriorates after an encephalogram which appears normal is difficult. Blackwood, Mosberg, and Robinson (1951) have described a case where there was an extensive cerebral glioma on necropsy and the cerebral arteriograms and the encephalogram had been normal. They mentioned several cases in the literature. We have had experience with a similar case. Dodge, Richardson, and Victor (1954) had a case where death followed soon after encephalography when there was an internal carotid artery thrombosis. Other patients with organic dementias may have their deaths precipitated by this method of investigation.

The investigation of the patient with an organic dementia is to some extent hazardous. The risks of encephalography are very small although its value in excluding a space-occupying process is exaggerated. Cerebral arteriography has become a popular alternative which in the right case yields incomparable information. However, serious complications and death may follow (Rowbotham, Hay, Kirby, Tomlinson, and Bousfield, 1953). The risk is greatest where there is cerebrovascular disease although it may be the only method of showing conclusively the occlusion of a major cerebral blood vessel. Air encephalography is by far the safer of the two methods of investigation.

The physician whose patient deteriorates after encephalography is in a quandary. He is naturally reluctant to inflict further diagnostic procedures on his patient. The probability is that the patient has some untreatable condition. In rare cases the investigation has precipitated a subdural haematoma and if there are any such doubts then the necessary burr holes should be made forthwith. It is possible that this complication is commoner than has been reported. We have discussed this problem with several neurologists and they were aware of the fact that a patient could have a normal encephalogram, die, and at necropsy a subdural haematoma be found. They concluded that the encephalogram had failed to reveal the lesion but it is more likely that the encephalogram was responsible for the lesion. Unfortunately we have not been able to obtain concrete evidence from them. It is extremely unlikely that a subdural haematoma could exist and be undetected by these special investigations. The same thing cannot be said for a cerebral neoplasm

\section{Summary}

A case is described of an adult who developed subdural haematoma after air encephalography Death occurred because the condition was nat diagnosed and treated soon enough.

The hazards of encephalography are considered in relation to the investigation of organic dementias.

\section{REFERENCES}

Blackwood, W., Mosberg, W. H., and Robinson, P. K. (1951).

Bucy, P. C. (1942)., Illinois med. J., 82, 300

Davidoff, L. M., and Dyke, C. G.'(1946). The Normal Encephalogram, 2nd ed. Lea and Febiger, Philadelphia.

Dodge, P. R., Richardson, E. P., and Victor, M. (1954). Brain, 77, 610 .

Lemere, F., and Barnacle, C. H. (1936). Arch. Neurol. Psychiat. (Chicago), 35, 990.

Lindgren, E. (1949). Acta radiol. (Stockh.), 31, 161.

McConnell, A. A. (1953a). Brain, 76, 473.

- (1953b). Ibid., 76, 485.

Rowbotham, G. F., Hay, R. K., Kirby, A. R., Tomlinson, B. E., and Bousfield, M. E. (1953).' J. Neurosurg., 10, 602.

Smith, H. V., and Crothers, B. (1950). Pediatrics, 5, 375.

Whittier, J. R. (1951). A.M.A. Arch. Neurol. Psychiat., 65, 463. 